\title{
A phase II, proof-of-concept pilot clinical study of a mouth rinse containing sandalwood album oil (SAO) for the prevention of oral and oropharyngeal mucositis associated with (Chemo-) radiation therapy in head and neck cancer patients
}

Chul S. $\mathrm{Ha}^{1, *}$, Ying Li ${ }^{1}$, Carol A. Jenkins', Qianqian Liu ${ }^{2}$, Joel E. Michalek², Somer Baburek ${ }^{3}$ and Corey Levenson ${ }^{3}$

'Department of Radiation Oncology, The University of Texas Health Science Center at San Antonio, 7703 Floyd Curl Drive, San Antonio, TX 78229 ${ }^{2}$ Department of Population Health Sciences, The University of Texas Health Science Center at San Antonio, 7703 Floyd Curl Drive, San Antonio, TX 78229

${ }^{3}$ Santalis Pharmaceuticals, 18618 Tuscany Stone, Suite 100, San Antonio, TX 78258

\begin{abstract}
Purpose: This study was intended to evaluate the efficacy in alleviating mucositis, safety and tolerability of sandalwood album oil (SAO) in patients treated with (chemo-) radiation therapy for head and neck cancer. Methods: Patients to be treated with (chemo-) radiation therapy for cancers of oral cavity/ oropharynx were asked to swish and gargle for 30 seconds, and spit, with SAO mouth rinse thrice a day throughout radiation therapy. Pain in the oral cavity/ oropharynx was measured using the numerical rating pain scale (NRPS) and mucositis using the RTOG scale every week. Our data were compared with two of the largest historical data bases. Results: Fourteen subjects were enrolled but six withdrew (4 due to taste/ smell, one due to fatigue, one due to perceived ineffectiveness). Among the eight who completed the course of SAO, 6 were treated with chemo-radiation and two with radiation only. IMRT was used for everyone. The median dose was 6,996 cGy in 33 fractions. There were no serious adverse events from the mouth rinse. The mean RTOG mucositis grades from weeks 3,6 and 9 were $1.125,2.125$ and 1.875. Two patients experienced mucositis $\geq 3$. The corresponding mean NRPS were $3.700,4.988$ and 3.875. Conclusions: The incidence of mucositis $\geq 3$ from the historical data bases ranged from $22 \%$ to $70 \%$. Distribution of our mean NRPS and RTOG mucositis data compared favorably against the historical data. Though SAO was difficult to use due to poor taste/smell, it was otherwise well tolerated and appears to exhibit enough signal to warrant further development.
\end{abstract}

Keywords: mucositis; sandalwood oil; radiation; chemotherapy; head and neck cancer

\section{Introduction}

Oral and oropharyngeal mucositis is an acute injury to the mucosal lining of the oral cavity and oropharynx associated with radiotherapy and chemotherapy. The inflammatory response to injury can cause pain and discomfort that result in dysphagia and odynophagia, excessive secretions and associated nausea. Subjects often require a temporary feeding tube to go through radiotherapy. The severity of radiation-induced mucositis is associated with the volume of mucosa irradiated, radiation dose and fractionation, concomitant use of chemotherapy, and subject factors such as tobacco and alcohol use, genetic predisposition and comorbidities. It has a negative impact on subjects' quality of life and compliance with treatment that often results in unintended radiation treatment breaks. It can also cause weight loss making radiation dose delivery less optimal secondary to significant tissue volume changes. These adverse outcomes can unfavorably affect radiotherapy local control rates.

Currently, no agents are clinically proven to prevent radiation-induced mucositis. The management strategies for oral and oropharyngeal mucositis are mainly supportive care including adequate pain control, use of protective coating agents or devices, feeding tube use to bypass the irradiated mucosa for nutrition and hydration, and other symptomatic management strategies [1, 2].

A number of "natural" and botanically-derived materials have been evaluated in clinical trials for their ability to reduce the incidence and severity of oral mucositis [3-12].

*Corresponding author: Chul S. Ha, M.D., Department of Radiation Oncology, The University of Texas Health Science Center at San Antonio, 7703 Floyd Curl Drive, San Antonio, TX 78229. Tel.: (210) 450-5566; Email: HaC@uthscsa.edu

Received 11 January 2020 Revised 14 February 2017 Accepted 22 February 2020 Published 28 February 2020

Citation: Ha CS, Li Y, Jenkins CA, Liu Q, Michalek JE, Baburek S, Levenson C. A phase II, proof-of-concept pilot clinical study of a mouth rinse containing sandalwood album oil (SAO) for the prevention of oral and oropharyngeal mucositis associated with (Chemo-) radiation therapy in head and neck cancer patients. J Clin Radiat Oncol. 2020; 3(1):1-5. DOI: 10.14312/23978511.2020-1

Copyright: (c) $2020 \mathrm{Ha}$ CS, et al. Published by NobleResearch Publishers. This is an open-access article distributed under the terms of the Creative Commons Attribution License, which permits unrestricted use, distribution and reproduction in any medium, provided the original author and source are credited. 
In addition, a commercially available cream (Vicco $\left.{ }^{\circledR}\right)$ containing turmeric and sandalwood oil has been studied in a clinical trial for its ability to reduce dermatitis in head and neck cancer patients being treated with radiation therapy [13]. These products have shown preliminary evidence of efficacy in the clinic.

Sandalwood album oil (SAO; also known as East Indian sandalwood oil (EISO)) is an essential oil that has previously been shown to be anti-inflammatory $[14,15]$ and active against a variety of pathogens, including Candida [16-18].

In traditional Indian (Ayurvedic) medicine, SAO was used as a treatment for inflammatory and eruptive skin diseases $[19,20]$. Traditional Chinese medicine also lists sandalwood as a treatment for gonorrhea, epigastric pain, and vomiting [21]. Sandalwood album oil has an excellent safety profile $[22,23]$ and its broad range of biological activities was recently reviewed [24]. The known anti-inflammatory and anti-microbial activity of SAO provided the rationale for studying its potential therapeutic use to prevent or reduce the severity of oral and oropharyngeal mucositis.

This study was intended to evaluate the efficacy in alleviating mucositis, safety and tolerability of SAO.

\section{Patients and methods}

The trial was conducted between October 9, 2015 and April 25, 2017 under IND 127,483 and was listed on clinicaltrials. gov (NCT02399228). It was approved by the Institutional Review Board at the University of Texas Health Science Center at San Antonio and all patients provided signed consent. Two of the authors (S.B., C.L.) were employed by the Santalis Pharmaceuticals (sponsor of the study) at the time of the study.

This trial was conducted as a single-center, open-label, proof of concept pilot study to evaluate the efficacy, safety and tolerability of a mouth rinse regimen for the prevention and treatment of oral mucositis. We intended to enroll 15 subjects to ensure that 10 subjects would complete the trial and be evaluable. This number of subjects limited the amount of financial resources to be committed. Accrual was slower than anticipated and the trial was halted once 14 subjects had been enrolled.

The SAO to be used in manufacturing of the botanical drug products for the Phase 2 clinical trial was obtained from Mount Romance Australia Pty Ltd (MR), 2 Down Road, Albany, Western Australia ("MR"). This drug substance complies with international standards for purity and identity (ISO 3518:2002). In addition, further testing for residual solvents, pesticides, heavy metals, adventitious toxins and other potential contaminants was carried out in compliance with the 2016 FDA Guidance for Botanical Drug Product Development.

The SAO is produced from East Indian sandalwood trees grown sustainably on Australian plantations by the Australian Sandalwood Oil Co. Pty Ltd ("ASC"), a subsidiary of MR. The drug substance was produced by traditional steam distillation under cGMP and the identity and purity of the botanical drug substance was fully documented in an accompanying Certificate of Analysis.

The formulation was mint flavored, sweetened with sorbitol and saccharin, alcohol-free and incorporated agents to help adhesion to the oral mucosa. The ingredients used in the formulation of the drug product batch are provided in Table 1.

Table 1 Mouth rinse composition.

\begin{tabular}{ll}
\hline Active ingredient & $0.25 \%$ Sandalwood album oil (SAO). \\
Inactive ingredients & $\begin{array}{l}\text { Polysorbate-80 NF, poloxamer 407 NF, xylitol } \\
\text { NF, sorbitol 70\% solution USP, menthol USP, } \\
\text { peppermint oil NF, sodium saccharin USP, } \\
\text { Glycerin USP, Xanthan Gum NF, Benzoic Acid, } \\
\text { Purified Water USP. }\end{array}$ \\
\hline
\end{tabular}

Subjects were included in the trial if they met all of the following criteria: head and neck cancer patients $\geq 18$ years of age with estimated survival $\geq 6$ months, involving the oropharynx or oral cavity, to undergo radiation therapy $\geq 60$ Gy with or without concurrent chemotherapy or biologic targeted therapy. No prior radiation therapy to the head and neck area or chemotherapy within the last year except for induction chemotherapy prior to the current course of radiation therapy was allowed. Patients had to be willing to refrain from using other treatments for oral mucositis until they consulted with the study investigator(s).

Subjects were excluded from the trial if they met any of the following criteria: preexisting mucositis from other causes, immunosuppressed (by nature of the diagnosis such as acquired immunodeficiency syndrome) or in chronic use of immunosuppressive drugs (such as those used for patients at risk of graft-versus-host disease after allogeneic transplant or for patients with lupus), known sensitivity to any of the constituents of the test product, ECOG performance status $\geq 3$, any condition that in the opinion of the investigator would confound the efficacy, safety and tolerability assessments (such as oral thrush), participation in any interventional clinical trial in the previous 30 days, pregnancy or breast feeding.

Once subject eligibility was confirmed, subjects started treatment on day one of their radiation. Subjects were given a bottle of the study medication and instructed to swish and gargle with $15 \mathrm{ml}$ for 30 seconds and spit out thrice daily, 15 minutes after each meal and refrain from eating the next hour. Subjects returned to the clinic once a week during radiation and then once every two weeks once their radiation had been completed until their mucositis resolved for the final study visit. Interim assessments, review of subject dosing diaries, weighing of the study medication bottle and assessment of concomitant medication and adverse events (AEs) were performed during these visits. Compliance was calculated by the patients' diary entries and also by weights of the study medication.

The primary efficacy evaluation was the severity of pain rated by the numerical rating pain scale (NRPS) and 
mucositis grade by RTOG criteria at Visit 7 (Day 36). Secondary efficacy evaluations included the severity of pain rated by the NRPS and mucositis grade by RTOG criteria at each study visit, frequency of the percutaneous endoscopic gastrostomy (PEG) tube for feeding during treatment and the onset and duration of mucositis (grade 0-4). The overall efficacy was determined by comparing the data to two of the largest historical controls, one from M.D. Anderson Cancer Center (MDACC) [25] and the other from Memorial Sloan Kettering Cancer Center (MSKCC) [26].

Safety was assessed by evaluating AEs with respect to the study drug. In addition, tolerability (taste and irritation) evaluations and quality of life survey were performed at each study visit. FACT/NCCN-Head \& Neck Symptom Index, a subset of the FACT- H\&N containing 10 items (FHNSI10) $[27,28]$, was used for quality of life measurement. Statistical methods were descriptive, given the nature of the pilot trial.

\section{Results}

Forty subjects were screened for participation in the trial. Fourteen subjects were enrolled. Six subjects withdrew from the study. Four of them objected to the taste/ smell of the mouth rinse, one withdrew due to overall fatigue and one withdrew because the subject didn't feel the study medication was providing any benefit. Eight subjects completed the course of treatment (nine visits/ 50 days of treatment). The median age for these eight patients was 53 years (range 42 - 78). Their gender was; male-6, female-2. The primary sites of disease were; tonsillar fossa -4 , base of tongue -2 , soft palate -2 . Their clinical stages per AJCC $7^{\text {th }}$ edition were; I-1, II-1, III-1, IVA-5. Seven of the eight subjects received a total of $69.96 \mathrm{~Gy}$ in 33 fractions during the course of their therapy; one subject received 60 Gy in 30 fractions (this subject received radiation only). Six of the eight subjects were also treated with concomitant chemotherapy. Three of them were treated with weekly cisplatin $40 \mathrm{mg} / \mathrm{m}^{2}$ (6, 6 and 7 cycles each). Two were treated with cisplatin $100 \mathrm{mg} / \mathrm{m}^{2}$ every 3 weeks ( 2 and 3 cycles each). One was treated with 6 cycles of weekly cetuximab at the starting dose of $400 \mathrm{mg} / \mathrm{m}^{2}$ followed by maintenance dose of $250 \mathrm{mg} / \mathrm{m}^{2}$. Two subjects were treated with radiation therapy only after wide local excision of the primary or biopsy.

The average compliance determined by weight change of the study medication bottle between subsequent visits to the clinic was $74 \%$ amongst those who completed the study. The average compliance determined by the patients' diary entries was 77\%. Two patients used PEG tubes for nutritional support during radiation therapy. Both patients had PEG tubes placed before radiation therapy: one for dysphagia and obstruction from tumor and the other for odynophagia and weight loss.

Of the eight subjects who completed the study, one subject experienced oral mucositis with a maximum RTOG score of 1 , five subjects experienced a maximum RTOG score of 2 , and two subject each experienced an RTOG grade of 3 or 4. Five subjects were positive for the presence of P16 (a marker for HPV infection), two were negative and one subject was not tested. The mean RTOG mucositis grades from weeks 3, 6 and 9 were 1.125, 2.125 and 1.875. The corresponding mean NRPS were 3.700, 4.988 and 3.875. Figure 1 represents the mean mucositis grades for the 6 patients treated with concurrent chemo-radiation in our series plotted over the MDACC data for patients treated for cancer of the oral cavity or oropharynx with radiation therapy alone or concurrent chemo-radiation therapy (Figure 1 from Elting et al.) [25]. Figure 2 represents the mean NRPS data for 6 patients treated with concurrent chemo-radiation in our series plotted over the mean oral pain grade data from MDACC for patients treated for cancer of the oral cavity or oropharynx with radiation therapy alone or concurrent chemo-radiation therapy (Figure 2 from Elting et al.) [25]. Figure 3 represents the plots for 3 most pertinent questions from the quality of life survey; (1) I can swallow naturally and easily, (2) I have pain in my mouth, throat or neck, (3) I can eat solid foods. Figure 3 included patients \#5 and \#7 who were excluded from Figures 1 and 2 since they were treated with radiation therapy only.

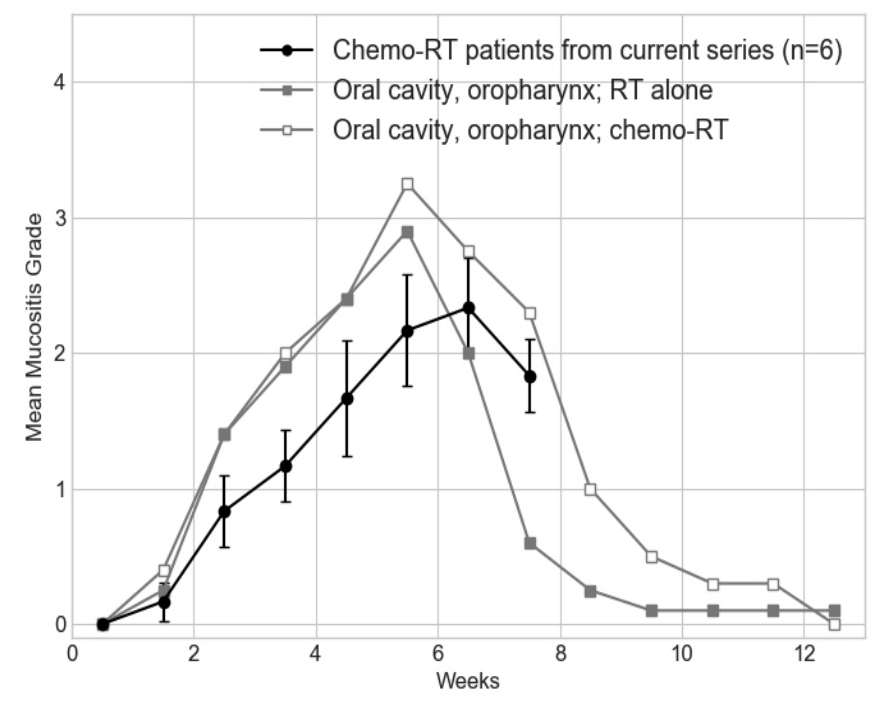

Figure 1 The mean mucositis data from our patients treated with concurrent chemo-radiation plotted over the corresponding data from MDACC.

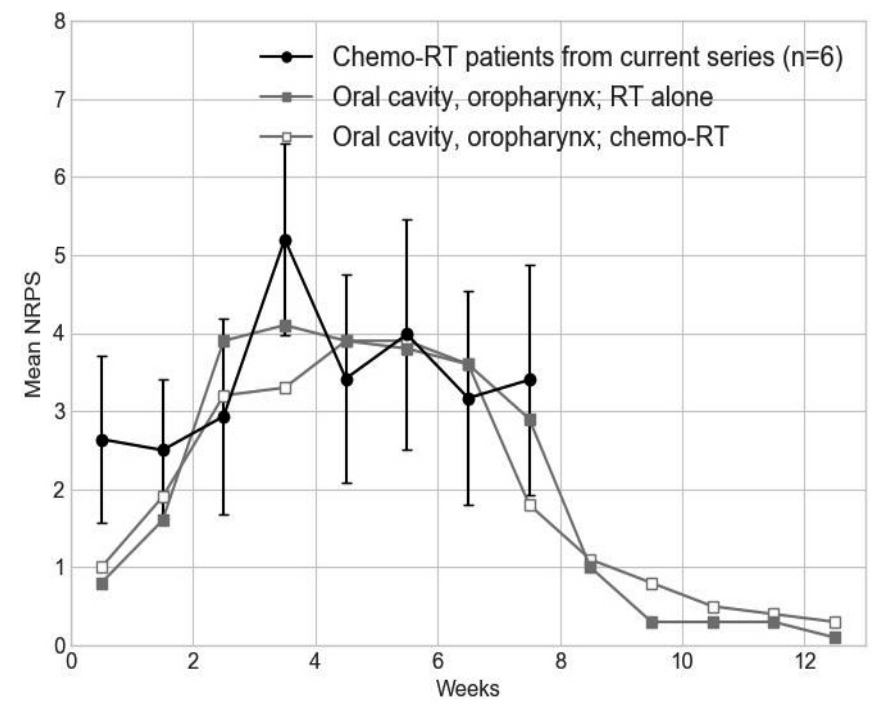

Figure 2 The mean NRPS data from our patients treated with concurrent chemo-radiation plotted over the corresponding data from MDACC. 


\section{I can swallow naturally and easily}

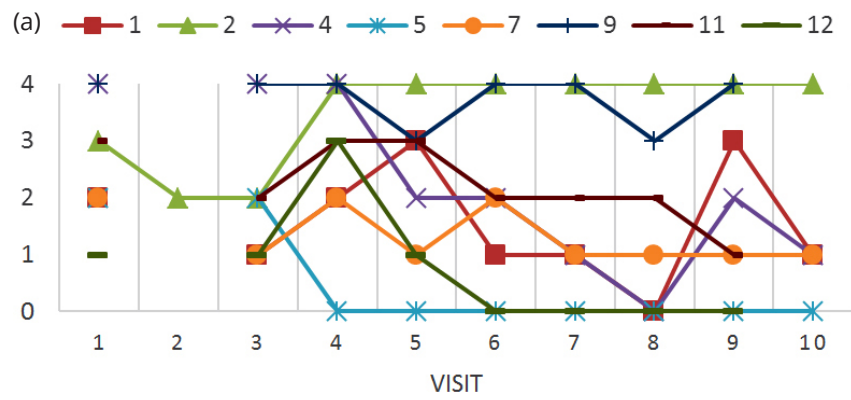

I have pain in my mouth, throat or neck

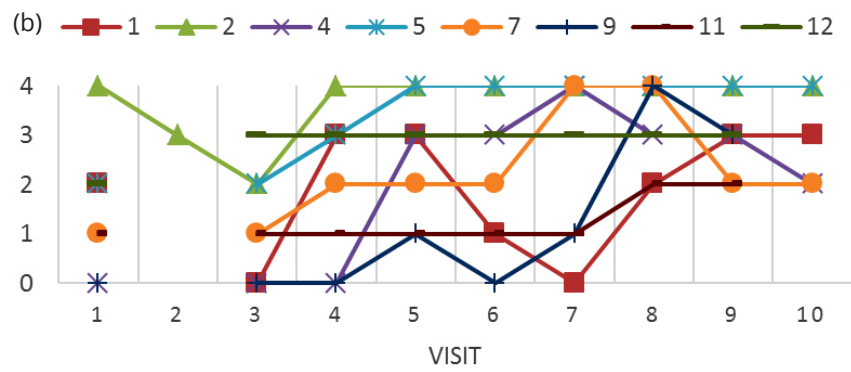

I can eat solid foods

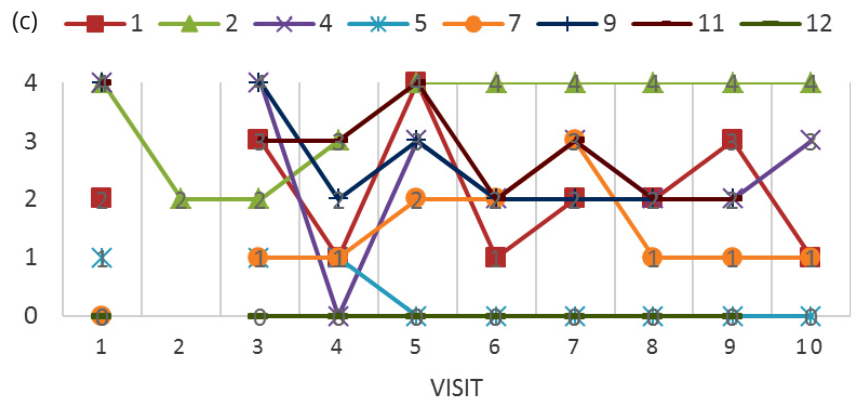

Figure 3a,b,c Data from 3 most pertinent questions from the FHNSI-10 quality of life questionnaires.

There were no serious adverse events that were deemed to be possibly or probably related to the study drug. Three subjects reported AEs of nausea, vomiting or both during trial participation. The AEs were assessed as possibly or probably related to the study drug. All events were mild in severity and resolved the same day of onset or after discontinuation of the study drug.

In spite of the addition of mint flavoring and sweeteners to the formulation, the distinctive, somewhat resinous taste of sandalwood oil was perceptible and the trial participants consistently rated the taste as either "fair" or "poor". Four participants experienced irritation of "mild" or "none". Three experienced "moderate" irritation and one participant experienced "severe" irritation. The taste and irritation results are presented in Table 2.

\section{Discussion}

SAO has a long history of use for medicinal purpose in different cultures. It has been recently demonstrated to have anti-inflammatory and anti-microbial effects. This clinical trial was undertaken as a proof of concept pilot study to assess the potential of SAO to prevent and/ or reduce oral and oropharyngeal mucositis associated with (chemo-) radiation therapy in head and neck cancer. Though the mouth rinse containing SAO was well tolerated in terms of serious adverse events, four of fourteen patients withdrew from the study due to poor taste/smell of the preparation. Two withdrew from other reasons. The remaining eight patients still rated the taste as "fair" or "poor" most of the time while the irritability from SAO was not as widely experienced as can be seen from the Table 2. SAO's effect on quality of life as presented in Figure 3 is difficult to interpret due to the small number of patients. The NRPS and RTOG mucositis data from the 8 patients who completed the study were compared with historical data from MDACC [25] and MSKCC [26]. The incidence of mucositis $\geq 3$ were $70 \%$ from MDACC and $22 \%$ from MSKCC while we had 2 out of 8 patients having mucositis $\geq 3$. Distribution of our mean RTOG mucositis data compares favorably against the MDACC data while distribution of our mean NRPS data essentially overlaps those of MDACC. Similar data are not available for direct comparison from the MSKCC.

Table 2 Taste (T) and irritation (I) by visit for each subject.

\begin{tabular}{|c|c|c|c|c|c|c|c|c|c|c|}
\hline Subject number & V1 & V2 & V3 & V4 & V5 & V6 & V7 & V8 & V9 & V10 \\
\hline 001 & & & $\begin{array}{l}\text { T: Fair } \\
\text { I: Mild }\end{array}$ & $\begin{array}{l}\text { T: Fair } \\
\text { I: None }\end{array}$ & $\begin{array}{l}\text { T: Poor } \\
\text { I: Mild }\end{array}$ & $\begin{array}{l}\text { T: Poor } \\
\text { I: Mild }\end{array}$ & $\begin{array}{l}\text { T: Poor } \\
\text { I: Mild }\end{array}$ & $\begin{array}{l}\text { T: Poor } \\
\text { I: Mild }\end{array}$ & $\begin{array}{l}\text { T: Poor } \\
\text { I: Mild }\end{array}$ & Not done \\
\hline 002 & & & $\begin{array}{l}\text { T: Good } \\
\text { I: Mild }\end{array}$ & $\begin{array}{l}\text { T: Fair } \\
\text { I: Mild }\end{array}$ & $\begin{array}{l}\text { T: Fair } \\
\text { I: Mod. }\end{array}$ & $\begin{array}{l}\text { T: Poor } \\
\text { I: Severe }\end{array}$ & $\begin{array}{c}\text { T: Fair } \\
\text { I: Severe }\end{array}$ & $\begin{array}{c}\text { T: Fair } \\
\text { I: Severe }\end{array}$ & $\begin{array}{c}\text { T: Fair } \\
\text { I: Severe }\end{array}$ & Not done \\
\hline 004 & & & $\begin{array}{l}\text { T: Poor } \\
\text { I: None }\end{array}$ & $\begin{array}{l}\text { T: Poor } \\
\text { I: None }\end{array}$ & $\begin{array}{l}\text { T: Poor } \\
\text { I: Mild }\end{array}$ & $\begin{array}{l}\text { T: Poor } \\
\text { I: None }\end{array}$ & $\begin{array}{l}\text { T: Poor } \\
\text { I: None }\end{array}$ & $\begin{array}{l}\text { T: Poor } \\
\text { I: None }\end{array}$ & $\begin{array}{l}\text { T: Poor } \\
\text { I: None }\end{array}$ & $\begin{array}{l}\text { T: Poor } \\
\text { I: None }\end{array}$ \\
\hline 005 & & & $\begin{array}{l}\text { T: Poor } \\
\text { I: None }\end{array}$ & $\begin{array}{l}\text { T: Poor } \\
\text { I: None }\end{array}$ & $\begin{array}{l}\text { T: Fair } \\
\text { I: None }\end{array}$ & $\begin{array}{l}\text { T: Fair } \\
\text { I: Mod. }\end{array}$ & $\begin{array}{l}\text { T: Fair } \\
\text { I: Mod. }\end{array}$ & $\begin{array}{l}\text { T: Poor } \\
\text { I: Mild }\end{array}$ & $\begin{array}{l}\text { T: Fair } \\
\text { I: Mild }\end{array}$ & $\begin{array}{l}\text { T: Fair } \\
\text { I: Mod. }\end{array}$ \\
\hline 007 & & & $\begin{array}{l}\text { T: Fair } \\
\text { I: None }\end{array}$ & $\begin{array}{l}\text { T: Fair } \\
\text { I: None }\end{array}$ & $\begin{array}{l}\text { T: Good } \\
\text { I: None }\end{array}$ & $\begin{array}{l}\text { T: Fair } \\
\text { I: None }\end{array}$ & $\begin{array}{l}\text { T: Good } \\
\text { I: None }\end{array}$ & $\begin{array}{l}\text { T: Fair } \\
\text { I: None }\end{array}$ & $\begin{array}{l}\text { T: Fair } \\
\text { I: None }\end{array}$ & $\begin{array}{l}\text { T: Good } \\
\text { I: None }\end{array}$ \\
\hline 009 & & & $\begin{array}{l}\text { T: Fair } \\
\text { I: None }\end{array}$ & $\begin{array}{l}\text { T: Fair } \\
\text { I: None }\end{array}$ & $\begin{array}{l}\text { T: Poor } \\
\text { I: Mild }\end{array}$ & $\begin{array}{l}\text { T: Poor } \\
\text { I: None }\end{array}$ & $\begin{array}{l}\text { T: Poor } \\
\text { I: Mild }\end{array}$ & $\begin{array}{l}\text { T: Poor } \\
\text { I: Mild }\end{array}$ & $\begin{array}{l}\text { T: Fair } \\
\text { I: None }\end{array}$ & \\
\hline 012 & & & $\begin{array}{l}\text { T: Fair } \\
\text { I: Mild }\end{array}$ & $\begin{array}{l}\text { T: Poor } \\
\text { I: Mod. }\end{array}$ & $\begin{array}{l}\text { T: Poor } \\
\text { I: Mod. }\end{array}$ & $\begin{array}{l}\text { T: Poor } \\
\text { I: None }\end{array}$ & $\begin{array}{l}\text { T: Poor } \\
\text { I: None }\end{array}$ & $\begin{array}{l}\text { T: Poor } \\
\text { I: Mild }\end{array}$ & $\begin{array}{l}\text { T: Poor } \\
\text { I: Mild }\end{array}$ & \\
\hline
\end{tabular}




\section{Conclusions}

Though we have a small number of patients and our data are compared to historical results from different institutions with many associated caveats, we believe the results are suggestive of benefit and exhibit enough signal to warrant further development of SAO as a potential alleviator of mucositis once the preparation is modified to be more palatable.

\section{Funding}

The Santalis Pharmaceuticals from San Antonio, Texas, funded the study. SB and $\mathrm{CL}$ from the Santalis Pharmaceuticals worked with the other co-authors from the University of Texas Health Science Center in study design, statistical analysis and manuscript edit/review.

\section{Conflict of interest}

CSH: Research grant from the Santalis Pharmaceuticals, Inc. for this study, Employment at the University of Texas Health Science Center at San Antonio, Texas; YL: Research grant from the Santalis Pharmaceuticals, Inc. for this study, Employment at the University of Texas Health Science Center at San Antonio, Texas; CAJ: Employment at the University of Texas Health Science Center at San Antonio, Texas; QL: Employment at the University of Texas Health Science Center at San Antonio, Texas; JEM: Employment at the University of Texas Health Science Center at San Antonio, Texas; SB: Employment at the Santalis Pharmaceuticals, Inc., San Antonio, Texas; CL: Employment at the Santalis Pharmaceuticals, Inc., San Antonio, Texas.

\section{Abbreviations}

SAO = Sandalwood Album Oil, NRPS = numerical rating pain scale, IMRT = Intensity Modulated Radiation Therapy, RTOG = Radiation Therapy Oncology Group, cGMP = current Good Manufacturing Practices, AEs = Adverse Events.

\section{References}

[1] Rosenthal DI, Trotti A. Strategies for managing radiation-induced mucositis in head and neck cancer. Semin Radiat Oncol. 2009; 19(1):29-34.

[2] Maria OM, Eliopoulos N, Muanza T. Radiation induced oral mucositis. Front Oncol. 2017; 7:89.

[3] Bertoglio JC, Calderon S, Lesina B, Pilleux L, Morazzoni P, et al. Effect of

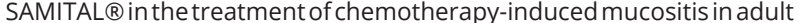
oncohematological patients. Future Oncol. 2013; 9(11):1727-1732.

[4] Kong M, Hwang DS, Yoon SW, Kim J. The effect of clove-based herbal mouthwash on radiation-induced oral mucositis in patients with head and neck cancer: a single-blind randomized preliminary study. Onco Targets Ther. 2016; 9:4533-4538.

[5] Kono T, Kaneko A, Matsumoto C, Miyagi C, Ohbuchi K, et al. Multitargeted effects of hangeshashinto for treatment of chemotherapy-induced oral mucositis on inducible prostaglandin E2 production in human oral keratinocytes. Integr Cancer Ther. 2014; 13(5):435-445.

[6] Maddocks-Jennings W, Wilkinson JM, Cavanagh HM, Shillington D. Evaluating the effects of the essential oils Leptospermum scoparium (manuka) and Kunzea ericoides (kanuka) on radiotherapy induced mucositis: a randomized, placebo controlled feasibility study. Eur J Oncol Nurs. 2009; 13(2):87-93.

[7] Morazzoni P, Petrangolini G, Bombardelli E, Ronchi M, Cabri W, et al.

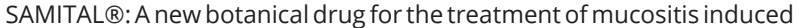
by oncological therapies. Future Oncol. 2013; 9(11):1717-1725.

[8] Mutluay Yayla E, Izgu N, Ozdemir L, Aslan Erdem S, Kartal M. Sage teathyme-peppermint hydrosol oral rinse reduces chemotherapy-induced oral mucositis: A randomized controlled pilot study. Complement Ther Med. 2016; 27:58-64.
[9] Rao S, Dinkar C, Vaishnav LK, Rao P, Rai MP, et al. The Indian Spice Turmeric Delays and Mitigates Radiation-Induced Oral Mucositis in Patients Undergoing Treatment for Head and Neck Cancer: An Investigational Study. Integr Cancer Ther. 2014; 13(3):201-210.

[10] Yarom N, Ariyawardana A, Hovan A, Barasch A, Jarvis V, et al. Systematic review of natural agents for the management of oral mucositis in cancer patients. Support Care Cancer. 2013; 21(11):3209-3221.

[11] You WC, Hsieh CC, Huang JT. Effect of extracts from indigowood root (Isatis indigotica Fort.) on immune responses in radiation-induced mucositis. J Altern Complement Med. 2009; 15(7):771-778.

[12] Pawar D, Neve RS, Kalgane S, Riva A, Bombardelli E, et al. SAMITAL ${ }^{\circledR}$ improves chemo/radiotherapy-induced oral mucositis in patients with head and neck cancer: results of a randomized, placebo-controlled, single-blind Phase II study. Support Care Cancer. 2013; 21(3):827-834.

[13] Palatty PL, Azmidah A, Rao S, Jayachander D, Thilakchand KR, et al. Topical application of a sandal wood oil and turmeric based cream prevents radiodermatitis in head and neck cancer patients undergoing external beam radiotherapy: a pilot study. $\mathrm{Br} J$ Radiol. 2014; 87(1038):20130490.

[14] Sharma M, Levenson C, Bell RH, Anderson SA, Hudson JB, et al. Suppression of lipopolysaccharide-stimulated cytokine/chemokine production in skin cells by sandalwood oils and purified alpha-santalol and beta-santalol. Phytother Res. 2014; 28(6):925-932.

[15] Sharma M, Levenson C, Clements I, Castella P, Gebauer K, et al. East Indian sandalwood oil (EISO) alleviates inflammatory and proliferative pathologies of psoriasis. Front Pharmacol. 2017; 8:125.

[16] Warnke PH, Becker ST, Podschun R, Sivananthan S, Springer IN, et al. The battle against multi-resistant strains: Renaissance of antimicrobial essential oils as a promising force to fight hospital-acquired infections. J Craniomaxillofac Surg. 2009; 37(7):392-397.

[17] Jirovetz L, Buchbauer G, Denkova Z, Stoyanova A, Murgov I, et al. Comparative study on the antimicrobial activities of different sandalwood essential oils of various origin. Flavour Fragr J. 2006; 21:465-468.

[18] Hammer KA, Carson CF, Riley TV. In-vitro activity of essential oils, in particular Melaleuca alternifolia (tea tree) oil and tea tree oil products, against Candida spp. J Antimicrob Chemother. 1998; 42(5):591-595.

[19] Chopra RN, Chopra IC, Verma BS. Supplement to glossary of Indian medicinal plants, Publication and Information Directorate (CSIR). New Delhi, India, 1969.

[20] Handbook of Ayurvedic Medicinal Plants. Boca Raton, FL: CRC Press; 1990.

[21] Sandalwood. Santalum album. The PDR for Herbal Medicine. 3rd ed. Montvale, NJ: Medical Economics Company; 2004. pp.702-703.

[22] Tisserand RB, Balacs T. Essential oil safety- a guide for health care professionals. Churchil Livingstone; 1995.

[23] Burdock GA, Carabin IG. Safety assessment of sandalwood oil (Santalum album L.). Food Chem Toxicol. 2008; 46(2):421-432.

[24] Moy RL, Levenson C. Sandalwood album oil as a botanical therapeutic in dermatology. J Clin Aesthet Dermatol. 2017; 10(10):34-39.

[25] Elting LS, Cooksley CD, Chambers MS, Garden AS. Risk, outcomes, and costs of radiation-induced oral mucositis among patients with head-and-neck malignancies. Int J Radiat Oncol Biol Phys. 2007; 68(4):1110-1120.

[26] Setton J, Caria N, Romanyshyn J, Koutcher L, Wolden SL, et al. Intensitymodulated radiotherapy in the treatment of oropharyngeal cancer: an update of the Memorial Sloan-Kettering Cancer Center experience. Int J Radiat Oncol Biol Phys. 2012; 82(1):291-298.

[27] List MA, D'Antonio LL, Cella DF, Siston A, Mumby $P$, et al. The performance status scale for head and neck cancer patients and the functional assessment of cancer therapy-head and neck scale. A study of utility and validity. Cancer. 1996; 77(11):2294-2301.

[28] Cella D, Paul D, Yount S, Winn R, Chang CH, et al. What are the most important symptom targets when treating advanced cancer? A survey of providers in the National Comprehensive Cancer Network (NCCN). Cancer Invest. 2003; 21(4):526-535. 